\title{
Novel technique for endoscopic submucosal dissection using an elastic thread delivery hood
}
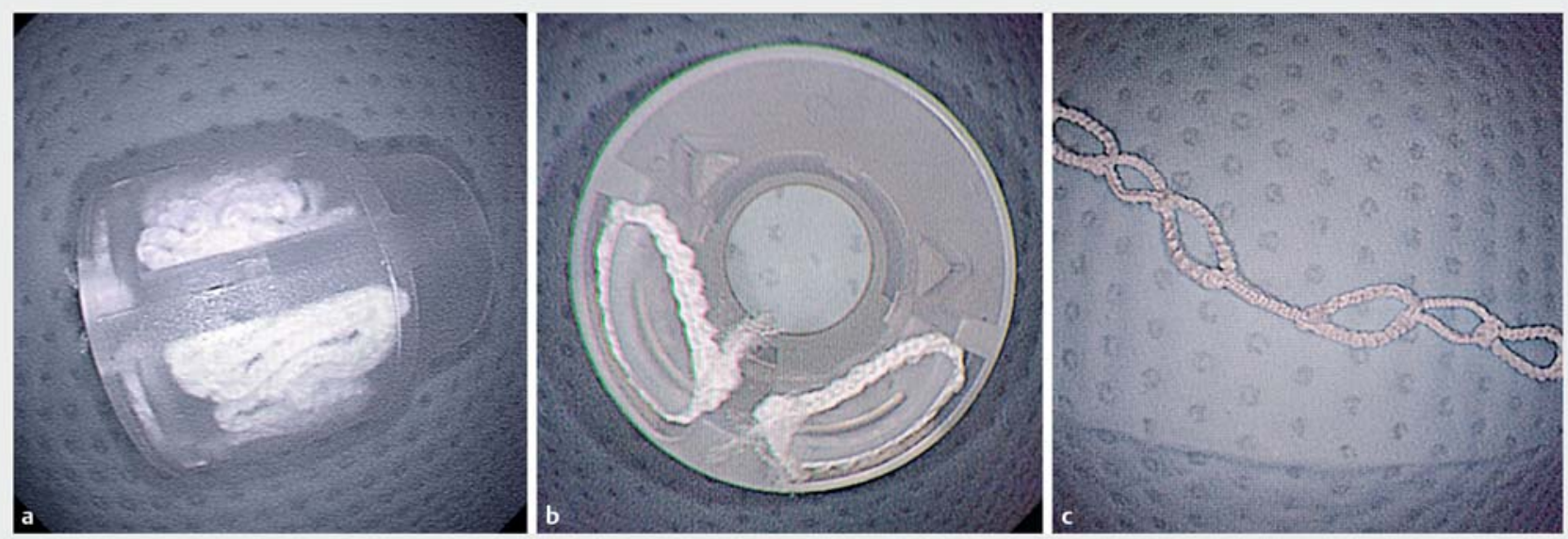

- Fig. 1 The Dual Traction Hood device (Adachi Co., Ltd., Osaka, Japan and Nomura Medical Device Co., Ltd., Nagano, Japan). a, b The device stores threads in its thin side pockets and hooks dual elastic threads at its tip. c The threads consist of multiple rings.

Because endoscopic submucosal dissection (ESD) is a challenging technique to perform, various traction techniques have been developed [1-5]. We designed a new hood - the Dual Traction Hood (Adachi Co., Ltd., Osaka, Japan and Nomura Medical Device Co., Ltd., Nagano, Japan) - which holds dual elastic threads in its thin side pockets ( $\triangleright$ Fig. 1 ). We performed ESD for a nongranular laterally spreading tumor in the ascending colon, in which submucosal fibrosis was predicted. The area had previously been tattooed by the referring doctor ( $\triangleright$ Fig.2). We attempted ESD using the Dual Traction Hood and endoclips. An endoscope attached to the hood was inserted to the lesion. After mucosal incision and submucosal dissection of the anal side, the first thread was grasped and fixed to the anal edge of the incised mucosa by the first endoclip through the endoscope. After the thread was released from the hood by pulling the endoscope back, the ring of the thread was grasped and fixed to the opposite colonic wall by the second endoclip ( $>$ Fig. 3 , > Fig. 4). A second thread was fixed in the same fashion. After these procedures, both sides of the lesion were retracted to the colonic lumen by the dual threads. Direct visualization of the peeling point facilitated safe submucosal dissection and one-piece resection ( $\triangleright$ Fig. $\mathbf{5}$, $\triangleright$ Video $\mathbf{1}$ ). No adverse event occurred either during or after the procedure.

This technique has several advantages. First, withdrawal or reinsertion of the endoscope is not necessary; therefore, the present hood is especially useful in the distal colon. Second, the direction and length of traction can be adjusted according to the individual situation because of the multiple rings in the threads. Third, because the thread is elastic it provides a suitable level of traction. The present technique can be a useful method of performing ESD.

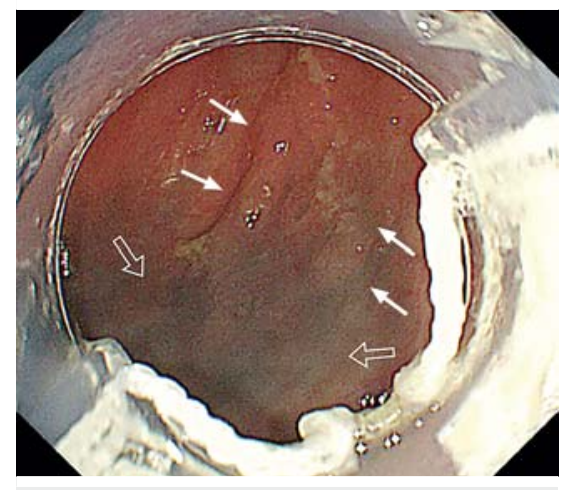

> Fig. 2 We performed endoscopic submucosal dissection for a nongranular laterally spreading tumor (thin arrows) in the ascending colon, in which submucosal fibrosis was predicted. The area had previously been tattooed by the referring doctor (thick arrows).

Competing interests

None

Endoscopy_UCTN_Code_TTT_1AQ_2AD 


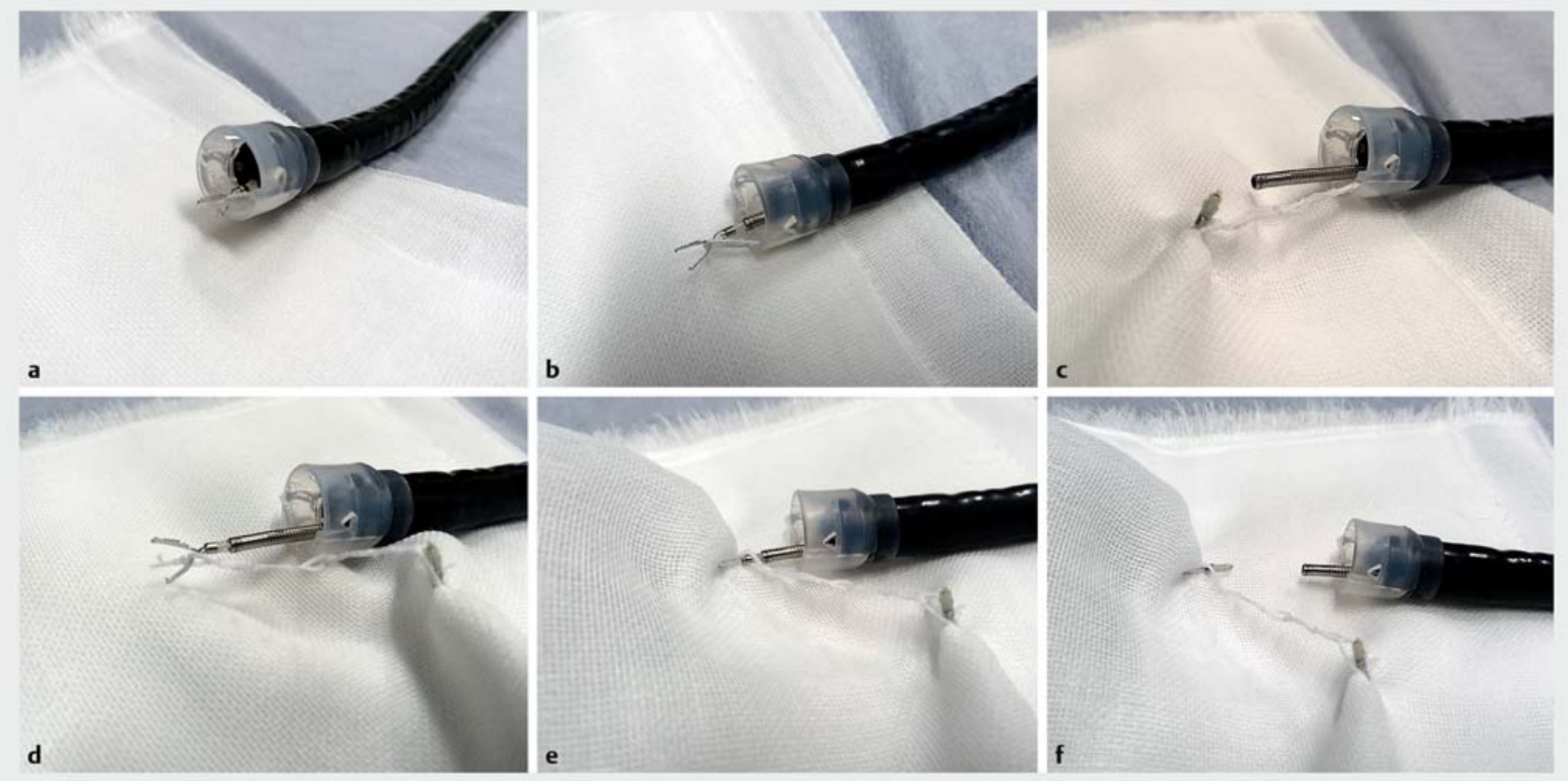

- Fig. 3 Demonstration of the traction process using the Dual Traction Hood device. a-c The thread is grasped by an endoclip and fixed to the lesion. $\mathbf{d}$, e After releasing the thread by pulling the endoscope back, the other ring of the thread is grasped and fixed to the opposite wall. $\mathbf{f}$ After the procedure, the lesion is retracted.

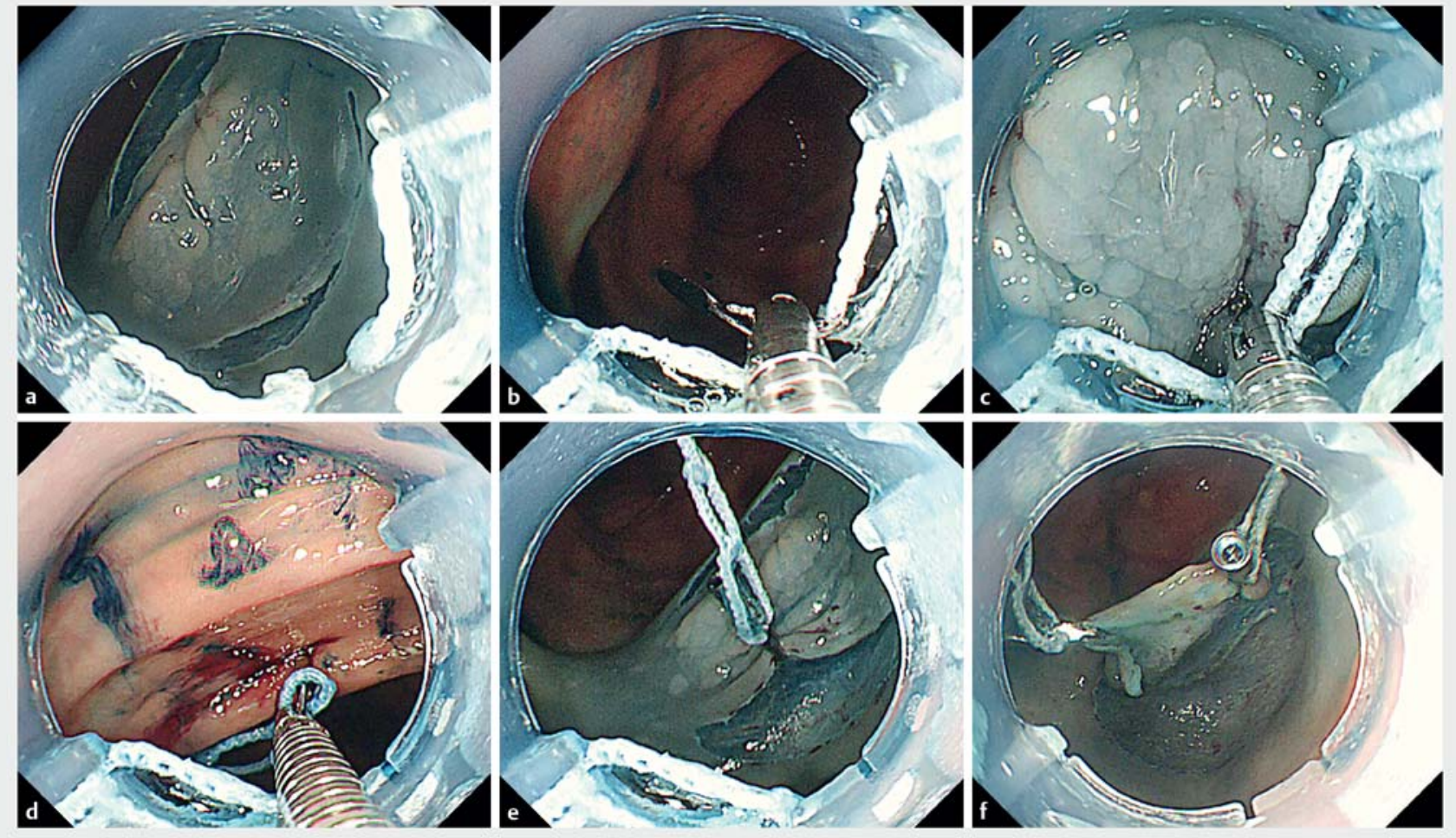

- Fig. 4 Endoscopic view of the traction process using the Dual Traction Hood device. a - c After mucosal incision and submucosal dissection of the anal side, the first thread was grasped and fixed to the anal edge of the incised mucosa by the first endoclip (SureClip; MC Medical, Tokyo, Japan) through the endoscope (PCF-260AZI; Olympus, Tokyo, Japan). d, e After the thread was released from the hood by pulling the endoscope back, the ring of the thread was grasped and fixed to the opposite colonic wall by the second endoclip. A second thread was fixed in the same fashion. $\mathbf{f}$ After these procedures, both sides of the lesion were retracted to the colonic lumen by the dual threads. 

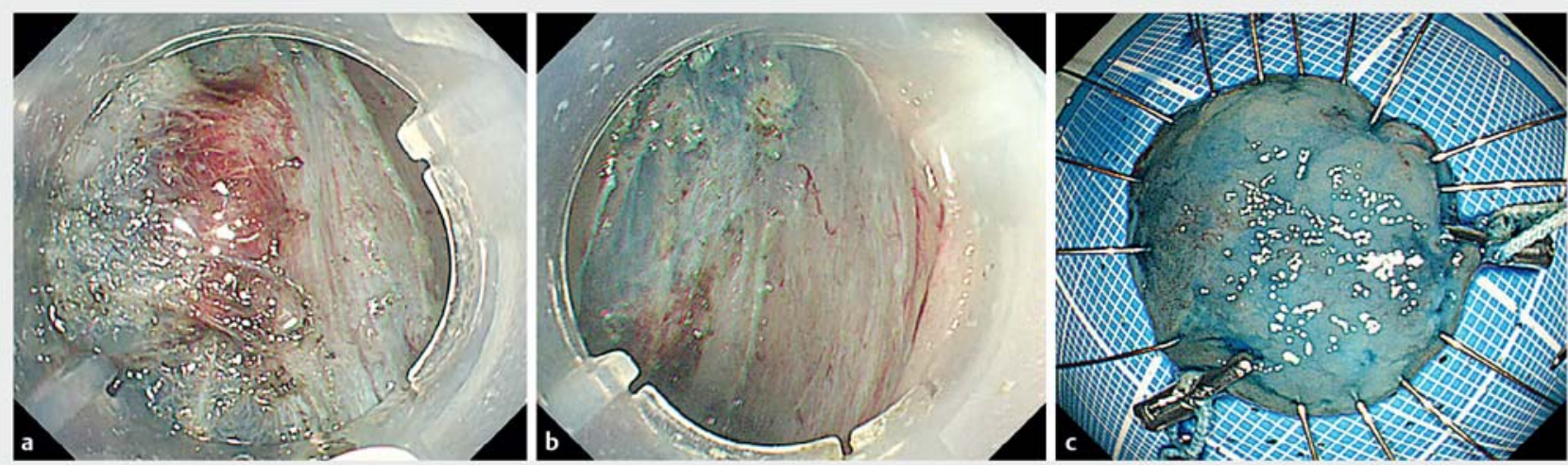

- Fig. 5 Endoscopic view after endoscopic submucosal dissection and resection. Direct visualization of the peeling point facilitated safe submucosal dissection and one-piece resection despite submucosal fibrosis.

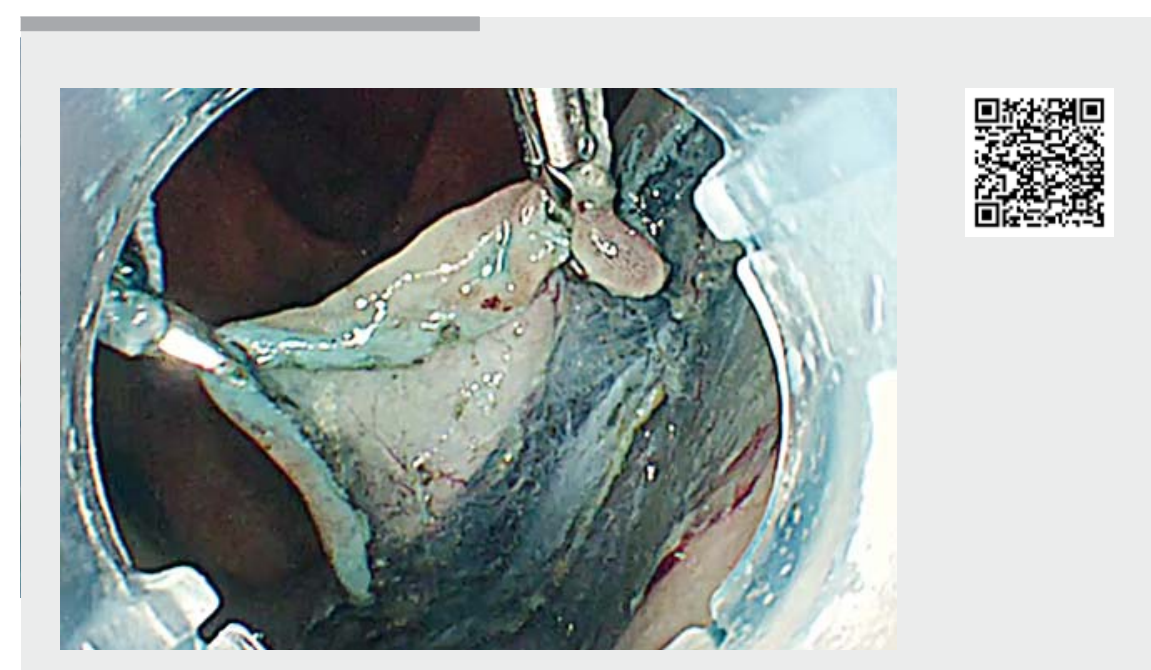

Video 1 Novel technique for endoscopic submucosal dissection using elastic thread delivery hood.

The authors

\section{Kinya Fujita, Masahiro Takeshita, \\ Eiji Moriyama, Satoshi Ochiai}

Tsukazaki Hospital, Gastroenterology, Himeji city, Hyogo, Japan

\section{Corresponding author}

\section{Kinya Fujita, MD}

Gastroenterology, Tsukazaki Hospital, 68-1

Waku, Aboshiku, Himeji City, Hyogo

Prefecture 671-1227, Japan

Fax: +81-79-2728550

kfujita1017@gmail.com
[4] Oyama T. Counter traction makes endoscopic submucosal dissection easier. Clin Endosc 2012; 45: 375-378

[5] Yamasaki Y, Takeuchi Y, Uedo $\mathrm{N}$ et al. Traction-assisted colonic endoscopic submucosal dissection using clip and line: a feasibility study. Endosc Int Open 2016; 4: E51-E55

\section{Bibliography}

DOI https://doi.org/10.1055/a-1045-4357

Published online: 2.12.2019

Endoscopy 2020; 52: E178-E180

(c) Georg Thieme Verlag KG

Stuttgart · New York

ISSN 0013-726X

\section{ENDOSCOPY E-VIDEOS}

https://eref.thieme.de/e-videos

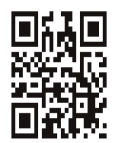

Endoscopy E-Videos is a free access online section, reporting on interesting cases and new techniques in gastroenterological endoscopy. All papers include a high quality video and all contributions are freely accessible online. endoscopic submuco early gastric cancer (with videos). Gastrointest Endosc 2009; 69: 10-15

[3] Sakamoto N, Osada T, Shibuya T et al. Endoscopic submucosal dissection of large colorectal tumors by using a novel spring-action S-O clip for traction (with video). Gastrointest Endosc 2009; 69: 1370-1374
This section has its own submission website at

https://mc.manuscriptcentral.com/e-videos 